\title{
AS PERIPÉCIAS DO QUATRO NA POLÍTICA BRASILEIRA
}

\author{
SEBASTIÃO VELASCO E CRUZ
}

Para começar, gostaria de fazer uma rápida reflexão a respeito da mágica, do mistério que no Brasil, da metade do século passado para cá, parece cercar o algarismo quatro. Vejam que coisa interessante. Estamos aqui no Cedec, em 2004, reunidos para comemorar mais um aniversário da revista Lua Nova, que inicia a sua brilhante carreira em 1984, ano da campanha pelas diretas, que fez soar o dobre de sinos pelo regime militar, iniciado em 1964, dez anos depois do suicídio de Vargas, em 1954. Eu não sou místico, mas, realmente, parece haver alguma coisa com esse algarismo.

O que eu havia pensado era em falar um pouco desses números, tirando da conjunção entre eles alguma coisa que pudesse nos servir também para olhar os próximos 20 anos, antecipar conversas que poderíamos ter - talvez possamos vir a ter - quando estivermos celebrando o quadragésimo aniversário da revista Lua Nova. E o atalho que vou seguir, para fazer essa reflexão, é lembrar a vocês a conhecida frase de Fernando Henrique Cardoso sobre a missão de seu governo, que seria a de "por fim à era Vargas". Na realidade ele não disse isso em 1994. Acho que foi em 1995. Mas ele deve tê-la pensado em 1994, e eu preciso desse quatro para dar maior harmonia a minha conversa.

Acho interessante relembrar esta frase porque, embora ela tenha soado muito natural na ocasião, não há nada de evidente nela. Imaginem um governante na Argentina falando em 1994 - ou 2004, não importa em encerrar a era Perón. Completamente descabido. Porque, por mais que a experiência do peronismo tenha marcado a história argentina, esse trabalho de demolição começou muito antes, e desde 1976 foi aplicadamente efetuado. A ditadura instalada na Argentina em 1966 buscava promover a modernização capitalista, manejando um Estado que, apesar de toda a campanha antiperonista, não tinha sido transformado nas suas bases. Mas 
em 1976, não. A tarefa da Junta Militar encabeçada por Vidella, de Martinez de Oz, de Alemani, e demais tecnocratas que a serviam, era passar o trator, transformar a Argentina de Perón em terra arrasada, para extirpar as condições que tornaram possíveis os conflitos que haviam convulsionado a Argentina até então. No Chile tampouco a frase de Fernando Henrique Cardoso faria qualquer sentido. Como imaginar, em 2000, o Presidente Lagos prometendo acabar com a herança de Arturo Alessandri? Não teria nenhum cabimento porque essa tarefa já tinha sido feita, a ferro e fogo, pela ditadura de Pinochet, instaurada pelo golpe militar de setembro de 1973 .

$\mathrm{O}$ que me intrigou quando eu pensei naquela frase, foi esta pergunta singela: por que Fernando Henrique falava em acabar com a era de Vargas e não acabar com a era dos generais? Fernando Henrique, intelectual que se tornou nacionalmente conhecido por sua oposição ao regime dos generais, assumiu o governo com forte mandato popular e em condições de fazer grandes reformas. Por que reformar a era Vargas e não a era dos generais?

A resposta para essa pergunta é fácil. Apesar de toda a violência produzida pelo golpe de $1^{\circ}$ de abril, entre o período de governo militar e o período anterior, as continuidades são muito claras. Vamos mencionar telegraficamente algumas apenas para apoiar o argumento. Empresas estatais: o BNDE, que tem esse papel tão grande até hoje na nossa história, não foi criado pelos militares, é de 1952. Houve em determinado momento a expectativa de que os militares fossem acabar com o BNDE, mas não foi isso que aconteceu, na verdade eles fortaleceram o banco. Como também não ocorreu aos militares, em momento algum, liquidar a Petrobrás. Pelo contrário, eles expandiram a Petrobrás e tantas outras empresas estatais. Então, aí não há uma descontinuidade. O sistema de enquadramento dos trabalhadores, de manejo, supervisão e controle das relações de trabalho, não foi criado pelos militares, veio de antes. $\mathrm{O}$ que os militares fizeram foi usar plenamente os recursos institucionais disponíveis para a realização de seus fins. Há muito tempo atrás, uma colega nossa, a Argelina Figueiredo, fez desse tema uma bela dissertação de mestrado, onde mostra exatamente como foi possível reprimir os sindicatos, expurgar os dirigentes sindicais que tinham se destacado nas mobilizações do pré-64 mantendo intacta a legislação sindical. Então, aí também há continuidade. De 1964 a 1984, a economia brasileira operou um salto no seu sistema produtivo, ampliou e aprofundou a sua indústria e fez isso com forte incorporação de capital estrangeiro. Mas, como todos nós sabemos, a passagem para esse modelo 
de desenvolvimento "dependente associado", para usar um termo que tinha tanto curso nos anos 1970, não se deu no período pós-64. Se quisermos marcar uma linha divisória, temos que voltar à década de 1950. E para fazer homenagem ao Carlos Lessa, autor de um brilhante estudo escrito em parceria com Sulamis Dain, talvez à década de 1920. Nesse trabalho, pensando no papel do Estado e da economia na América Latina, mas tomando como referência basicamente o Brasil, os dois autores mostram que desde os anos 1920 as relações entre o Estado, os capitais nacionais e o capital estrangeiro eram regidas por uma espécie de pacto. Pacto segundo o qual os grupos dominantes, os empresários, as classes proprietárias no Brasil, abrem espaços em alguns lugares para a liderança da empresa estrangeira (sobretudo na indústria), guardando para si o controle de áreas de atividades que proporcionam renda e por isso mesmo se mantêm durante muito tempo como áreas reservadas, onde o capital estrangeiro não penetra ou faz em um grau muito reduzido. Então há grande continuidade aí também.

No plano econômico e social, o regime militar aprofundou um modelo cujo perfil já estava claramente desenhado no período anterior. É verdade, os governos militares, especialmente o de Castello Branco, introduziram uma série de inovações institucionais importantes, como o FGTS, e a correção monetária, por exemplo. Mas ao contrário do que aconteceu em outros países, como o Chile de Pinochet, o que buscavam era aperfeiçoar o padrão de economia capitalista existente, não destruí-lo, para criar um outro, inteiramente diferente, sobre os seus escombros. Se abstrairmos a mudança política, seria possível fazer uma narrativa do Brasil tomando este evento, o golpe de 64, como uma ocorrência menor.

O problema - e é aí é que a conversa se torna interessante - é que não podemos fazer essa abstração. Porque uma das coisas fundamentais na sociedade brasileira do pré-64 era a sua forte dinâmica democratizante. De 1946 a 1964, o Brasil cresceu enormemente e com o crescimento econômico cresceu também a participação das classes populares no processo político. A intervenção desses setores na vida política não era um fenômeno novo. Basta lembrar o episódio de 1935 e o final do Estado Novo. Com a Guerra Fria veio o refluxo: em 1947 foi extinto o Partido Comunista e na esteira desse ato as organizações populares foram fortemente reprimidas. Mas alguns anos mais tarde o contexto era outro. Depois do primeiro quatro da nossa história, o suicídio de Vargas, as classes populares voltam em grande estilo à cena política brasileira e desde a renúncia de Jânio Quadros, em 1961, elas se tornam um 
elemento central na conjuntura de crise que vai desembocar no golpe de 64 . O golpe veio para sufocar as demandas de incorporação dos setores populares na vida política para triunfar definitivamente sobre essa força perturbadora: o impulso democratizante da sociedade brasileira. A essa tarefa os autores do golpe se lançaram de imediato, e com enorme zelo. No tocante aos setores populares, sobretudo no campo, a violência foi a regra No trato com os políticos e com as organizações que serviam de canais de expressão para os setores médios a sua ação foi muito mais contida, oscilante. Ela se apresentou inicialmente como uma intervenção cirúrgica, limitada no tempo e em seu alcance. Depois foi se ampliando em ondas, até chegar, em dezembro de 1968, com o AI-5, no confisco da política, na instauração de uma ditadura sem disfarce.

Mas, contrariamente ao que alguns analistas chegaram a acreditar, os militares que deram o golpe não pretendiam com isso liderar uma volta ao passado. Eram autoritários, porém modernizantes. Queriam uma indústria forte e uma economia capitalista em crescimento. Por isso, delegaram o comando da política econômica a civis e criaram uma rede de segurança para defendê-los de todo o tipo de pressão, mesmo daquelas que vinham da caserna. E nesse plano eles foram muito bem sucedidos.

O ciclo de crescimento que começa em 1968 e se prolonga até o início da década de 80 tem a ver com uma série de fatores, internos e externos, grande parte dos quais sem relação alguma com a orientação da política econômica. Não importa. O certo é que, por sua duração e por sua intensidade, ele implicou em mudanças profundas na estrutura da economia e da sociedade brasileira. A urbanização acelerada é uma das expressões desse processo. A enorme expansão das classes médias assalariadas e da força de trabalho empregada na indústria são duas outras. Aí reside a grande ironia. Alterando modos de vida, abrindo novos horizontes, redefinindo expectativas e visões de mundo de parcelas expressivas da população, essas mudanças estruturais acabaram por induzir a emergência de forças sociais que dariam novo impulso à dinâmica democratizante que se procurou extirpar com o golpe de 64. Com todos os problemas que o Carlos Estevam mencionou em termos de orientações políticas e ideológicas, o certo é que os militares não previram a força com que a contestação política se manifestou a partir de 1974 - outro 4 importante em nossa história. 1974, como todos se lembram, foi o ano da grande vitória eleitoral da oposição. No ano anterior Ulisses Guimarães tinha se lançado como anticandidato à Presidência da República, a fim de denunciar o ritual da sucessão encenado pela ditadura. A partir daí não 
houve como segurar. Três anos depois o movimento operário voltava à cena com a campanha pela reposição salarial. Em 1978 as ações se multiplicaram. Em 1979 veio a anistia, em 1980 a terceira e a mais longa greve dos metalúrgicos de São Bernardo. Em 1984 houve a explosão da campanha pelas Diretas. A essa altura, os militares não tinham mais condições de permanecer no poder. Nem sequer tinham condições de indicar o civil que deveria sucedê-los. Eles perderam efetivamente o controle do processo. Essa é a primeira parte da história.

Não vou me estender sobre a outra parte. Direi apenas que hoje, vinte anos depois do fim do regime militar, quando voltamos a refletir sobre nossa trajetória histórica, nos vemos diante dos mesmos desafios. O desafio em 1964, como em 1984, foi o de como garantir o avanço, o desenvolvimento do país com a necessária incorporação das grandes parcelas da população brasileira condenadas a viver em condições subumanas. Essa situação não foi superada. Na realidade nós vivemos ainda como antes - ou mais até do que antes - em uma sociedade opressiva. O desafio central em 1964 era o de como transformar isso. Hoje, como em 1984, esse continua sendo o nosso grande desafio. O desenvolvimento econômico é um dos elementos, um dos ingredientes essenciais da solução que buscamos. O outro é o fortalecimento das instituições e práticas da democracia política. E aqui, é preciso reconhecer, apesar de todas as vicissitudes, das idas e vindas, tivemos alguns êxitos. Nessa minha pequena exposição eu falei de um opositor, de um dos mais bem sucedidos opositores da ditadura, Fernando Henrique Cardoso, presidente duas vezes, e falei - não nomeei, mas falei - do outro, expressão da força dos trabalhadores organizados, o nosso presidente Lula. Apesar disso, a perplexidade é geral, os desafios estão aí.

Para terminar, gostaria de dizer ainda uma palavra sobre a nossa revista. Quando penso nos próximos vinte anos na perspectiva de uma revista como a Lua Nova, eu me digo que podemos ter mil dificuldades, mas uma não teremos, que é a de montar uma agenda. Em sua análise, o Carlos Estevam centrou fogo nos elementos internos, nos componentes domésticos de nossa crise. Mas nós não podemos perder de vista que as questões que ele levantou não são questões brasileiras, são questões mundiais. Questões de um mundo que se reorganiza desde meados dos anos 1980, e que se reorganiza de uma forma tal que a sustentação dessas idéias fundamentais - a idéia de nação, a idéia de um Estado que expresse a vontade autônoma de um povo - não têm lugar assegurado. Não tem lugar assegurado na prática e não tem lugar assegurado na teoria. 


\section{INTERVENÇÃO NO DEBATE}

Sebastião V. e Cruz: Em relação às perguntas dirigidas à mesa deste debate e às respostas do Carlos Estevam, eu quero dizer que vejo a coisa por um outro ângulo, e isso me deixa um pouco mais otimista, com a percepção de outras possibilidades. Eu tendo a olhar esse assunto pelo ponto a que cheguei ao final da minha exposição. $\mathrm{O}$ mundo atravessa um processo de reestruturação. Essa reestruturação que tem um nome "movimento de globalização" - passa pela criação de disciplinas internacionais, que levam ao questionamento de instituições nacionais, à redução do grau de liberdade dos Estados. Mas, por isso mesmo, ela esbarra em uma série de pontos de resistência. Essa resistência se manifesta na ação de grupos e setores sociais determinados mas, em última análise, ela se situa nas coletividades nacionais, porque a própria idéia de nação e de soberania nacional é negada por aquele movimento. A não ser uma soberania e uma nação - não é preciso dizer qual -, que é o tronco sobre o qual tudo se apóia. Esse movimento de globalização é contraditório e não se realiza jamais plenamente. Ele se impõe através de lutas, embates, cujos resultados não são predeterminados. Eles variam entre os diferentes setores de atividade, e entre os países. Se você comparar o Brasil com outros Estados que entraram nessa onda, um pouco antes ou um pouco depois - como o México, que o Brasílio [prof. Brasílio Sallum, presente ao debate] conhece tão bem - você vai perceber que nós estamos, apesar de tudo, nos movimentando em um terreno diferente.

Eu fiquei deprimido com os acontecimentos de duas semanas atrás, quando foi demitido o Lessa, depois da septuagésima notícia de sua demissão. É isso mesmo, depois de ter sido demitido setenta vezes pela imprensa, ele foi demitido de fato, e ninguém saiu à rua em sua defesa, não aconteceu nada. É deprimente, sem dúvida. Mas eu faço a seguinte pergunta: como é possível que durante um ano e meio - foram quase dois anos - tenhamos presenciado, nesses tempos bicudos, uma instituição como o BNDES com uma gestão como a do Lessa? Você não tem isso no México, não tem isso na Argentina, não tem isso em outros paises. E não teve isso no Brasil durante o governo Fernando Henrique Cardoso. Você sabe quantos presidentes o BNDES tivemos nos dois governos do Fernando Henrique Cardoso? Acho que foram oito. A instabilidade da instituição era muito grande porque no governo FHC a linha de comando era muito clara, e não dava espaço para um verdadeiro banco de desenvolvimento. Agora estamos diante de outra lógica. A demissão do Lessa levou à pergunta: e o que 
vai acontecer depois? No dia seguinte foi feito um comentário com o qual eu concordo: "ganharam, mas não levaram". A conspiração era derrubar o Lessa e instalar no BNDES alguém com a cara do Francisco Gross, um homem do mercado financeiro para colocar o banco no bom caminho do qual tinha se afastado. Não sei se isso vai acontecer. Aparentemente não é essa a orientação que está predominando.

Acho que, apesar de todos os problemas, o Brasil é um país muito grande. E a demanda de afirmação nacional, ainda que não se expresse hoje através de uma força política importante e reconhecível, está aí. Ela aparece nesse ou naquele ato, nessa ou naquela iniciativa de política. Mas aparece também em manifestações de interesse pela questão nacional que eu percebo em pessoas muito mais jovens do que eu. Isso não surge do nada. A existência desse interesse é uma razão a mais para resistirmos ao ceticismo. No meu entender, existe uma hierarquia nos onze itens que o Carlos mencionou. De minha parte, eu começaria pela questão da Nação e a questão do Estado. Não é possível democracia com Estado fraco. O Estado fraco não é solo para democracia, é solo para a opressão social. Estado dos fortes contra os fracos na sociedade.

SEBASTIÃO VELASCO E CRUZ é professor titular do Departamento de Ciência Política da Unicamp. 